\title{
Exploring the Influence of Cultural Values on the Acceptance of Information Technology: An Application of the Technology Acceptance Model
}

\author{
Sylnovie Merchant \\ Lynchburg College, Lynchburg, VA, USA
}

\author{
merchant.s@lynchburg.edu
}

\begin{abstract}
While there has been a great deal of research on the application and implementation of Information Technology (IT), there is less research on the variables which can contribute to the successful diffusion and implementation of IT within an organization. This paper looks at the relationship between the cultural/work values of the people involved and IT adoption. Three cultures and the correlation of their cultural/work orientations and the adoption of IT via the Technology Adoption Model (TAM). Findings suggest a correlation between some of the variables in the two models used.
\end{abstract}

Keywords: culture, technology acceptance

\section{Introduction}

A fact of life for many companies, foreign and domestic, large and small, is how to be competitive in the global marketplace. This is especially so in the application of information technology to their operations on a global scale. The expanding interdependent global economy and the accompanying changes in the structure of competition are forcing many companies to seek new ways to manage their businesses. There is a growing need for coordination in the areas of product design, production, and distribution across country units in order to achieve global economies of scale and provide consistent quality service to global corporate customers. This growth of multinational business has been accompanied by significant increases in the adoption of new technologies around the world. Yet, the development of IT in a global environment is complex and significantly different from IT development within a domestic environment. Due to the differences existing in the political/legal, social/cultural, technological, and economic dimensions of the host country, as well as affiliate country=s environments, the implementation of global IT could pose major problems. Therefore, companies need to develop not just a generally favorable

Material published as part of this publication, either on-line or in print, is copyrighted by the Informing Science Institute. Permission to make digital or paper copy of part or all of these works for personal or classroom use is granted without fee provided that the copies are not made or distributed for profit or commercial advantage AND that copies 1) bear this notice in full and 2) give the full citation on the first page. It is permissible to abstract these works so long as credit is given. To copy in all other cases or to republish or to post on a server or to redistribute to lists requires specific permission and payment of a fee. Contact Publisher@InformingScience.org to request redistribution permission. culture but also specific cultural characteristics to maximize the use of technology to the performance of their employees (Yip, 1995).

The purpose of this paper is to explore IT adoption and its relationship with national culture. Specifically, it is argued that knowledge of the cultural orientation of organizational employees will greatly facilitate IT adoption and implementation, which in turn will con- 
tribute to a successful company. Hunger and Wheelen (1995) point out that an optimal culture is one that best supports the mission and strategy of the company of which it is a part. Given the fact that 25 percent to 50 percent of an employee's behavior on the job is culturally determined (Gannon, 1994), one needs to understand the cultural values behind this employee. The critical challenge is to help employees relate better to global problems and opportunities (Garland \& Farmer, 1986).

\section{Culture}

As early as 1952, researchers identified more than 160 definitions of culture, and in 1994, it was estimated that culture has been defined in approximately 400 ways (Ferraro, 1994). This paper will simply supply the reader with a brief introduction to the notion, rather than explore the many definitions. However, there is a common view in research concerning the basic meaning of culture: individually, we are all different, but share similar experiences with those who grew up in the same surroundings, in the same type of society as us. In this way, there are cultural differences between, for example: nations, regions, social classes, generations, organizations, etc.

An operational definition of Culture, therefore, is: (1) something that is shared by all, or almost all members of some social group; (2) something that the older members of the group try to pass on to the younger members; and (3) something (as in the case of morals, laws and customs) that shapes behavior, or that structures one's perception of the world. Consequently, this is why a) culture is always a collective phenomenon (to be distinguished from the individual level), b) deep cultural values change relatively slowly over time, and c) collective cultural values influence the definition of laws, management styles, political institutions, the construction of theories and ways of carrying out research (Francesco \& Gold, 1998). The key terms are the values and expectations that individuals bring into the work place.

Therefore, increased knowledge about such factors as what motivates people from other cultures in how they will react under certain circumstances, in which way they make decisions and want shorter decisions to be made, the way they communicate, how they want contracts to be stipulated, how their performance is evaluated, etc., can contribute to a reduction of the already high levels of uncertainty linked to cross-cultural management. Furthermore, this knowledge, or cultural competence, can help reduce costs linked to negotiation and the quality of productivity through an improvement of the management of human resources.

Researchers have developed frameworks to classify the cultures of the world in order to understand its influence (Harrison, 1975; Hofstede, 1980; Kluckhohn \& Strodtbeck, 1961; Trompenaars,1993). These frameworks are averages or norms of the value systems that compose a culture rather than exact descriptions. In other words, they represent approximate expected behavior in a culture. Obviously, not everyone in a particular culture behaves in the same way. In fact, there is often greater variation within single cultures than across cultures. Each of the cultural frameworks attempt to explain cultural differences. Some are built upon, and elaborate on, the work of others, resulting in some overlap. None of the frameworks is absolutely correct or better than the others, yet each contributes to our understanding of why people from different cultures behave differently.

It is argued that culture is the most useful variable in discussing differences in how people behave, and that communication is central to culture and the management of organizational behavior. Language is intricately linked to culture, and communication expressions challenges cultural values. In essence, organizations are communication systems. Without effective communication, organizations experience difficulty and even failure. As Fiedler, Grover, \& Teng (1996) pointed out, the key contribution of IT is to support the firm, “... and this can be achieved if the capabili- 
ties and characteristics of the IT structure matches the requirements and the nature [culture] of the organization."

\section{IT and Cultural Relationships}

Technology has made global teamwork an everyday reality for thousands of people. Software developers in the United States and Europe work with programmers in India to design systems and write code; bankers trade a common book of US government around the world 24 hours a day; medical specialists collaborate with local doctors in remote regions to diagnose and treat rare conditions; and country managers coordinate production plans and marketing campaigns across Europe. Video conferences, voice mail, the Internet, corporate intranets, groupware, and virtual team rooms are just some of the technologies that enable people to work together no matter where they are based, giving them access to countless new business opportunities (Benson-Armer \& Hsieh, 1997).

Yet many corporations have invested millions of dollars in top-of-the-line technology, only to be disappointed when there is no commensurate improvement in performance. Although technology creates business openings by enabling us to communicate with colleagues and business partners in far-flung places, we cannot rely on technology alone to capture them. Human relations are paramount (Benson-Armer \& Hsieh, 1997).

The successful adoption of information technology has been an area of interest in IT research for many years. One of the most often used instruments to measure the acceptance of new technology and the intention to use it is the Technology Acceptance Model (TAM).

The Technology Acceptance Model (TAM), developed by Davis (1989) was designed to analyze an individual $=\mathrm{s}$ willingness to accept information technology. The TAM proved that acceptance of new computing technology was based primarily on two major characteristics of that technology. These were perceived usefulness and perceived ease of use. Perceived usefulness was defined as the degree to which individuals believed that using the technology would enhance their job performance. Perceived ease of use was defined as the degree to which an individual believed that using a system or learning to use a system would be free of effort (Davis, 1989). This research was considered a major breakthrough in explaining the successful adoption of new technology. Recently, the extended model of technology acceptance (TAM2) was developed by Davis and Venkatesh (2000). The extended model included subjective norms defined as "a person's perception that most people who are important to him/her think s/he should or should not perform the behavior in question" (Fishbein \& Azjen, 1975, p. 302). However, the original is the one most commonly used by researchers in attempting to understand cultural differences in information technology.

In the first study to validate the TAM outside of North America, Straub, Keil, \& Brenner, (1997) tested the TAM in Switzerland, the United States, and Japan. The authors found that of the three countries, they were only able to validate its use in Switzerland and the United States, and not Japan. A second study attempted to validate the TAM in five Arabic countries (Rose \& Straub, 1998). The authors found that the TAM transferred successfully to the Arab world. However, they did not attempt to relate TAM to any cultural instrument. In fact, the authors, and others, point out that caution should be exercised when interpreting these findings since social and cultural norms could predict IT use (Rose \& Straub, 1998; Straub et al, 1997). When investigating the aspect of culture, IT researchers have primarily relied upon the national cultural dimensions by Hofstede (1980), which reflects a "national character" portrait of a society.

Straub (1994) used Hofstede's dimensions to study the diffusion of e-mail and fax in the United States and Japan. He found that the uncertainty avoidance characteristic of the Japanese caused 
them to be less likely to accept e-mail. He also concluded that culture played an important role in the adoption and use of electronic communications media.

Robichaux and Cooper (1998) developed a research model in order to identify the interaction of culture and group support systems (GSS). Their research made use of Hofstede's cultural dimensions and the TAM and focused on North American countries. Although, the authors did not empirically test their model, they did develop several propositions.

Other studies on the influence of cultural on GSS use include Watson, Ho, \& Raman (1994) study of Singaporean groups use of GSS and Mejias, et al (1996-97) comparison of GSS groups and non-GSS groups in the U.S and Mexico. However, in both of the studies, the technology was already accepted and in use. The research measured this use and the effect of culture on how the groups used the system.

Grover, et al. (1994) also made use of Hofstede's cultural dimensions in their study investigating the similarities and differences in IT resource, practice, and its perceived success in the United States, France, and Korea. The main findings were that Koreans looked upon IT in a more traditional and operational manner than their US and French counterparts and that the perceived benefits of IT use varied among the three countries.

In a study of technological innovations in China, Kururanga et al (2001) used the TAM to explain the intention to adopt technologies in China. The research attempted to establish a relationship between the factors in innovation diffusion theory and the TAM in determining what would influence adoption. They found a link between perceived ease of use and usefulness, but made no attempt to factor analyze the data they collected.

More recently, Srite and Karahanna (2006) used the extended TAM with Hofstede's cultural dimensions as moderators to study the role of national cultural values on the acceptance of information technology. However, their data was collected from graduate and undergraduate students who attended the same university. They did not draw their sample directly from specific countries.

\section{Research Framework}

Individuals bring cultures of origin to work that reflect their particular ongoing histories in various cultural contexts, such as national cultures (Brannen, 1994). Cross-cultural research has established that national culture explains between 25 and 50 percent of variation in attitudes (Gannon et al, 1994) and is also related to social behaviors such as aggression, conflict resolution, social distance, helping, dominance, conformity, and obedience (Triandis, 1994), as well as decision-making and leadership behaviors (Hofstede, 1980; Shane, 1994). In cognitive terms, national culture is viewed as a set of shared meanings transmitted by a set of mental programs that control responses in a given context (Hofstede, 1980). The basic thesis of a cognitive approach to culture is that processing frameworks acquired in one culture persist and influence behavior even though contextual circumstances change. In this manner, culture guides our choices, commitments, and standards of behavior (Erez \& Earley, 1993). Team collaboration requires information exchange and collective information processing (Gibson, 2001) and is therefore rich in cognitive content; however, since cultural contexts around the globe are infused with very different cognitive frameworks, team metaphors are likely to vary across national cultures.

It is not enough to simply suggest that concepts vary across organizational cultures; it is also important to examine systematic variation due to specific aspects of culture. Researchers have demonstrated that patterns of orientations (O'Reilly et al., 1991) and practices (Hofstede, 1990) can be used to explain the differences in organizational cultures. Kabanoff and colleagues (Kabanoff et al., 1995; Kabanoff \& Holt, 1996) identified a set of nine orientations-performance, reward, 
authority, leadership, teamwork, commitment, normative orientation, participation, and affiliation - that can be discerned from organizational documents such as annual reports and demonstrated that different patterns of orientations were associated with different ways of portraying and communicating change. Several of the nine orientation provided in Kabanoff's work overlap conceptually with national culture, however, many researchers recommend distinguishing between national culture and organizational culture (Hofstede, 1990). For example, the authority, leadership, normative, and commitment dimensions capture content similar to power distance and teamwork, participation, and affiliation are conceptually similar to collectivism. In light of this overlap, we focus here on two orientations identified by Kabanoff and colleagues-performance and rewards that have the least conceptual overlap with national cultural values as portrayed in the intercultural literature and thus allow clear distinctions between the two constructs. In addition, these two dimensions have strong implications for the elements of teamwork that are embedded in metaphors. The first dimension, performance, captures the degree to which an organization emphasized achievement, service, and efficiency and has been related to differences in attitudes toward change across organizations (Kabanoff \& Holt, 1996).

This paper relies upon a conceptual framework outlined by Harrison (1975). Harrison's strength is that his study is directed to employees currently on the job. He identified four organizational ideologies: (1) Power Orientation, (2) Role Orientation, (3) Task Orientation, and (4) Person Orientation.

The Power-Oriented organization wants to dominate its industry, is extremely competitive and desires to have employees loyal and supportive, while it will be the benevolent authority for all. Individuals with this orientation are quite comfortable in taking and receiving orders from their superiors.

The Role-Oriented organization aspires to be rational and orderly in all of its dealings. There is a preoccupation with legality, legitimacy, and responsibility. Employees are expected to follow the detailed policies and procedures of the organization, and conversely, individuals who are oriented this way desire for clear rules and regulations to follow - and that is what they will follow.

The Task-Oriented organization strives to achieve its goals. The important and determining factor is that the organization $=\mathrm{s}$ structure, functions, and activities are all evaluated in terms of their contribution to achieving the desired goal. Nothing is permitted to get in the way of accomplishing the task, and employees feel that tell me what needs to be done, give me the tools and I'll do it.

Finally, the Person (Self)-Oriented organization exists primarily to serve the needs of its members. The organization attempts to provide growth to its members by recognizing that a more experienced, trained individual will contribute more to the organization, and employees enjoy this personal approach.

The strength of Harrison=s framework is threefold. One, he has developed a valid and reliable instrument that can be used to classify the four orientations, and has been used to predict success in joint venture organizations in information technology (Cartwright \& Cooper, 1989). At the same time, he has provided the basis for the potential benefits for both the organization and the individual operating under the four orientations. Finally, the respondents to his instrument are only people employed at the time, therefore reflecting work/cultural values toward various workrelated factor, rather than merely individuals within a particular country.

For individuals, given their orientation to the type of manager they desire and are comfortable with, as shown in Table 1, the characteristics of the four orientations provide them with varying degrees of: (1) security against economic, political, and psychological deprivation, (2) opportunities for voluntary commitment to worthwhile goals, and (3) opportunities to pursue one $=\mathrm{s}$ own 
growth and development independent of organization goals. In essence, one can assess the compatibility of individuals and the four types of orientations, and how the individual with adopt change. This research is concerned with the "voluntariness" of the individual to make a commitment.

For organizations, the four ideologies listed in Table 2 provide them with varying degrees of (1) effective response to dangerous, threatening environments, (2) dealing rapidly and effectively with environmental complexity and change, and (3) internal integration and coordination of effort, if necessary, at the expense of individual needs. In essence, selecting one culture over another may serve the interests of the organization better in its competition with rivals.

Table 1: Interests of the Individual

\begin{tabular}{|l|c|c|c|}
\hline ORIENTATION & $\begin{array}{c}\text { Security against } \\
\text { economic, political and } \\
\text { psychological depriva- } \\
\text { tion }\end{array}$ & $\begin{array}{c}\text { Opportunities for } \\
\text { Voluntary com- } \\
\text { mitment to worth- } \\
\text { while goals }\end{array}$ & $\begin{array}{c}\text { Opportunities to pur- } \\
\text { sue one's own growth } \\
\text { separate from firm's } \\
\text { goal }\end{array}$ \\
\hline POWER & Low & Low & Low \\
\hline ROLE & High & Low & Low \\
\hline TASK & Moderate & High & Low \\
\hline SELF & High & High & High \\
\hline
\end{tabular}

Table 2: Interests of the Organization

\begin{tabular}{|l|c|c|c|}
\hline ORIENTATION & $\begin{array}{c}\text { Effective response to } \\
\text { dangerous \& threat- } \\
\text { ening events }\end{array}$ & $\begin{array}{c}\text { Dealing rapidly and } \\
\text { effectively with com- } \\
\text { plexity \& change }\end{array}$ & $\begin{array}{c}\text { Internal unity - if } \\
\text { necessary at the ex- } \\
\text { pense of people }\end{array}$ \\
\hline POWER & High & Moderate to Low & High \\
\hline ROLE & Moderate to Low & Low & High \\
\hline TASK & Moderate to High & High & Moderate \\
\hline PERSON & Low & High & Low \\
\hline
\end{tabular}

\section{Methodology}

The cultural orientations instrument of Harrison (1975) and the Technology Acceptance Model (1989) were administered to employees in the United States, France, and China. The Harrison (1975) instrument asked the respondents to indicate their basic cultural orientation to 15 jobrelated categories. Some items asked such as (1) what makes a good boss, (2) what makes a good subordinate, (3) how should decisions be made, (4) how should conflict be resolved, etc. Some items asked such as (1) what makes a good boss, (2) what makes a good subordinate, (3) how should decisions be made, (4) how should conflict be resolved, etc. The TAM asked participants to consider new technology introduced into their organization that they directly interacted with. Questions pertaining to demographics were also included. 
The instruments distributed in China and France were translated and then back translated to check accuracy. Organizations were chosen through personal and professional contacts, and they included two major international accounting/consultant firms, a manufacturing company, a data processing company, a health company, and an insurance company. The surveys were distributed to a convenience sample. A total of 598 usable responses were collected: 136 from France, 186 from the United States and 280 from China. The demographics of the respondents are shown in Table 3 (a through e).

Table 3: Demographics - Sample Characteristics

\begin{tabular}{|c|c|c|}
\hline \multicolumn{3}{|c|}{ (a) Organizational Position } \\
\hline Country & Managers & Non-managers \\
\hline United States & $16.4 \%$ & $83.6 \%$ \\
\hline China & $17.6 \%$ & $82.4 \%$ \\
\hline France & $50.5 \%$ & $49.5 \%$ \\
\hline
\end{tabular}

\begin{tabular}{|c|c|c|}
\hline \multicolumn{3}{|c|}{ (b) Public Or Private Sector Employment } \\
\hline Country & Public & Private \\
\hline United States & $56.8 \%$ & $43.2 \%$ \\
\hline China & $52.9 \%$ & $47.1 \%$ \\
\hline France & $22.6 \%$ & $77.4 \%$ \\
\hline
\end{tabular}

\begin{tabular}{|l|c|c|c|}
\hline \multicolumn{4}{|c|}{ (c) Years Employed } \\
\hline Years & Unites States & China & France \\
\hline Less than 1 & $10.4 \%$ & $5.9 \%$ & $10.8 \%$ \\
\hline 1-3 Years & $16.9 \%$ & $17.6 \%$ & $11.8 \%$ \\
\hline 4-6 Years & $18.6 \%$ & $19.9 \%$ & $9.7 \%$ \\
\hline More than 6 & $54.1 \%$ & $56.6 \%$ & $67.7 \%$ \\
\hline
\end{tabular}

\begin{tabular}{|l|c|c|c|}
\hline \multicolumn{4}{|c|}{$(\mathrm{d})$ Age } \\
\hline \multicolumn{1}{|c|}{ Age of Employees } & Unites States & China & France \\
\hline Under 20 & $2.7 \%$ & $1.5 \%$ & $1.1 \%$ \\
\hline $20-24$ & $12.0 \%$ & $16.9 \%$ & $19.4 \%$ \\
\hline $25-29$ & $29.0 \%$ & $16.9 \%$ & $9.7 \%$ \\
\hline $30-34$ & $15.8 \%$ & $19.1 \%$ & $12.9 \%$ \\
\hline $35-39$ & $20.2 \%$ & $17.6 \%$ & $14.0 \%$ \\
\hline $40-49$ & $12.6 \%$ & $10.3 \%$ & $29.0 \%$ \\
\hline $50-59$ & $5.5 \%$ & $8.1 \%$ & $5.4 \%$ \\
\hline 60 and over & $2.2 \%$ & $9.6 \%$ & $8.6 \%$ \\
\hline
\end{tabular}




\begin{tabular}{|l|c|c|c|}
\hline \multicolumn{4}{|c|}{ (e) Gender and Marital Status } \\
\hline \multicolumn{1}{|c|}{ Gender and Marital Status } & Unites States & China & France \\
\hline Male Unmarried & $28.4 \%$ & $20.6 \%$ & $26.9 \%$ \\
\hline Female Unmarried & $24.0 \%$ & $44.9 \%$ & $4202 \%$ \\
\hline Male Married & $20.8 \%$ & $9.6 \%$ & $16.1 \%$ \\
\hline Female Unmarried & $26.8 \%$ & $25.0 \%$ & $10.8 \%$ \\
\hline
\end{tabular}

As one can see from the tables, the respondents reflect a typical work-force in a particular country. There are public sector and private employees, young and old, new and experienced, married and single, and managers and non-managers. With these data, one is able to assess what these national contingent of employees desire in work-related orientations.

\section{Findings}

Exploratory factor analysis (EFA) was used to identify the TAM factors for each country. EFA is a method used to capture measurement of items in order to identify the factor structure underlying the data. The EFA performed uses the maximum likelihood extraction with an oblique rotation of the factors (Pedhazur \& Schmelkin, 1991). The criterion used to determine the meaningful factor loadings (standardized regression coefficients) has a lower limit of 0.5 which is considered indicative of a sufficiently strong relationship of an item with its factor for exploratory research (Sharma, 1996).

It was hoped that the TAM would be an excellent predictor of an instrument that could be used in other cultures. Unfortunately, it only factored correctly to the America sample (see tables 4 through 6).

\begin{tabular}{|l|l|l|}
\hline \multicolumn{3}{|c|}{ Table 4: France } \\
\hline & $\begin{array}{c}\text { Perceived Ease } \\
\text { of Use }\end{array}$ & $\begin{array}{c}\text { Perceived Use- } \\
\text { fulness }\end{array}$ \\
\hline P5 & $\mathbf{0 . 9 4 5 7 6}$ & 0.12596 \\
\hline P2 & $\mathbf{0 . 9 3 2 6 9}$ & 0.26271 \\
\hline P4 & $\mathbf{0 . 7 1 7 5 1}$ & -0.26877 \\
\hline P1 & $\mathbf{0 . 6 4 0 5 7}$ & -0.41729 \\
\hline P3 & $\mathbf{0 . 5 9 9 3 3}$ & -0.48565 \\
\hline P6 & $\mathbf{0 . 5 5 6 1 4}$ & -0.50112 \\
\hline E2 & -0.02056 & $\mathbf{0 . 8 8 9 2 6}$ \\
\hline E4 & 0.40515 & $\mathbf{0 . 8 8 0 6 4}$ \\
\hline E3 & -0.07178 & $\mathbf{0 . 7 9 1 4 2}$ \\
\hline E6 & -0.07990 & $\mathbf{0 . 5 4 3 9 0}$ \\
\hline E1 & -0.11776 & 0.39665 \\
\hline E5 & -0.39179 & -0.39428 \\
\hline
\end{tabular}

\begin{tabular}{|l|l|l|}
\hline \multicolumn{3}{|c|}{ Table 5: China } \\
\hline & $\begin{array}{c}\text { Perceived } \\
\text { Ease of Use }\end{array}$ & $\begin{array}{c}\text { PerceivedUse- } \\
\text { fulness }\end{array}$ \\
\hline P5 & $\mathbf{0 . 8 1 3 7 2}$ & -0.19050 \\
\hline P3 & $\mathbf{0 . 7 7 1 3 3}$ & -0.31245 \\
\hline P1 & $\mathbf{0 . 6 2 0 5 4}$ & 0.28026 \\
\hline E3 & $\mathbf{0 . 6 0 2 4 6}$ & -0.00330 \\
\hline E5 & $\mathbf{0 . 5 9 2 7 1}$ & 0.26947 \\
\hline E4 & $\mathbf{0 . 4 8 9 4 4}$ & 0.01808 \\
\hline P6 & 0.32180 & 0.27230 \\
\hline P4 & -0.01868 & $\mathbf{0 . 7 7 8 7 0}$ \\
\hline E2 & 0.09886 & $\mathbf{0 . 7 6 4 3 0}$ \\
\hline P2 & 0.00785 & $\mathbf{0 . 6 5 2 2 9}$ \\
\hline E1 & -0.21084 & $\mathbf{0 . 6 2 9 8 2}$ \\
\hline E6 & 0.38718 & $\mathbf{0 . 5 8 0 3 5}$ \\
\hline
\end{tabular}




\begin{tabular}{|l|l|l|}
\hline \multicolumn{3}{|c|}{ Table 6: US } \\
\hline & $\begin{array}{c}\text { Perceived } \\
\text { Ease of Use }\end{array}$ & $\begin{array}{c}\text { PerceivedUse- } \\
\text { fulness }\end{array}$ \\
\hline P2 & $\mathbf{0 . 9 7 6 5 3}$ & -0.01155 \\
\hline P5 & $\mathbf{0 . 9 6 1 1 9}$ & -0.05306 \\
\hline P4 & $\mathbf{0 . 9 5 7 1 6}$ & -0.03632 \\
\hline P6 & $\mathbf{0 . 9 3 1 6 8}$ & 0.06387 \\
\hline P1 & $\mathbf{0 . 9 0 3 3 6}$ & -0.04638 \\
\hline P3 & $\mathbf{0 . 8 6 6 2 9}$ & 0.09623 \\
\hline E1 & -0.26470 & $\mathbf{0 . 9 4 8 8 7}$ \\
\hline E6 & 0.01519 & $\mathbf{0 . 8 6 5 3 5}$ \\
\hline E3 & 0.12258 & $\mathbf{0 . 8 3 8 4 7}$ \\
\hline E2 & -0.06442 & $\mathbf{0 . 8 2 8 2 9}$ \\
\hline E4 & 0.17384 & $\mathbf{0 . 7 6 5 7 0}$ \\
\hline E5 & 0.33081 & $\mathbf{0 . 7 2 6 4 3}$ \\
\hline
\end{tabular}

It was also hoped that the Harrison Instrument could be related to the TAM for the three cultures. However, it was not possible to perform the analysis since the TAM could not be validated for the Chinese and the French. The Harrison findings indicate that the French reflected an overwhelming orientation toward Task, with 14 of the 15 in that category; with 1orientation toward Role. Americans reflected 12 of 15 toward Task, 2 toward Role, and 1 toward Self. Finally, the Chinese reflected 7 toward Task, 6 toward Role and 2 toward Power. Tables 7 through 8 show the orientations of each of the countries.

Table 7: Opportunities for Voluntary commitment to worthwhile goals

\begin{tabular}{|l|c|c|c|c|}
\hline \multicolumn{1}{|c|}{ Country } & $\begin{array}{c}\text { Power } \\
\text { Moderate to Low }\end{array}$ & $\begin{array}{c}\text { Role } \\
\text { Low }\end{array}$ & $\begin{array}{c}\text { Task } \\
\text { High }\end{array}$ & $\begin{array}{c}\text { Self } \\
\text { High }\end{array}$ \\
\hline United States & 0 & 2 & $\mathbf{1 2}$ & 1 \\
\hline China & $\mathbf{2}$ & $\mathbf{6}$ & $\mathbf{7}$ & 0 \\
\hline France & 0 & 1 & $\mathbf{1 4}$ & 0 \\
\hline
\end{tabular}

Table 8: Dealing Rapidly and Effectively with Complexity and Change in IT Country and Harrison Orientation

\begin{tabular}{|l|c|c|c|c|}
\hline \multicolumn{1}{|c|}{ Country } & $\begin{array}{c}\text { Power } \\
\text { Moderate to Low }\end{array}$ & $\begin{array}{c}\text { Role } \\
\text { Low }\end{array}$ & $\begin{array}{c}\text { Task } \\
\text { High }\end{array}$ & $\begin{array}{c}\text { Self } \\
\text { High }\end{array}$ \\
\hline United States & 0 & 2 & $\mathbf{1 2}$ & 1 \\
\hline China & $\mathbf{2}$ & $\mathbf{6}$ & $\mathbf{7}$ & 0 \\
\hline France & 0 & 1 & $\mathbf{1 4}$ & 0 \\
\hline
\end{tabular}

Clearly, Harrison's orientation in table 7 show France as the one nation that would be the first to voluntary accept change to worthwhile goals, with the US next, both with a majority of Task ori- 
entations. On the other hand, China, with its mix of Role and Task, would be much slower to adopt change. In table 8, similar results can be noted in the orientations to the adoption of IT.

\section{Discussion}

From an organizational standpoint, with the introduction of technology into the organization, an orientation of Task and Self would be ideal as they are oriented toward "Dealing rapidly and effectively with complexity \& change", as reflected in the Table 8 above. From this, obviously the French and Americans would most likely adopt new innovation to deal with changes thrust upon them. For the Chinese, while receptive to new innovations, their orientation of Task and Role would be less enthusiastic to adopt as rapidly as the French or Americans.

While the two instruments did not reflect correlation, individual elements include the correlation of 13 Harrison orientations with elements of Perceived Usefulness and Ease of Use. That is, France in one Role orientation correlated with "ease of use." The United States reflected 3 Task Orientations with "increase productivity," "enhance effectiveness on the job," and with "learning to use would be easy," and "be flexible to work with." China had 4 Role Orientations correlated with 4 of the 6 Perceived Usefulness elements and 5 of the Perceived Ease of Use elements. It also had 3 Task Orientations correlate with 3 Perceived Usefulness elements and 2 Perceived Ease of Use elements, and 1 Power Orientation with one Perceived Usefulness elements. This suggests that portions of the two instruments reflect similarities that could be explored in future research.

Even with this difference, however, we can learn from this study the variables of importance to nationalities around the world and from that prepare ourselves on the best approach to introduce change into the organization from an IT standpoint. The findings of this study are supported by the few studies undertaken in cross-culture IT application. For example, Kitchell (1995) found that culture is predictive of technology adoption. Straub et al., (1997), in their study of the TAM across cultures, concluded that "there is a growing need to understand how cultural factors might affect multi-national organization's ability to adopt and utilize IT" (p. 9). In a separate study by Kettinger et al., (1995) on cross-national IS Quality perceptions, they found that there exist an AAsian factor@ with differing definitions of IS. A very recent study of the attitudes of three separate cultures on the adopting of IT found that culture is a crucial element that can determine acceptance or not, and that we need to consider cultural resistance to technologies (Brown et al., (1998). This model can assist in understanding cultural differences.

\section{Conclusion}

In summary, IT has been instrumental in contributing to the effectiveness of organizations striving for competitive advantage. New developments and applications of IT have assisted many organizations, in many industries, to maximize the potential to exceed previous expectations on a global scale from a competitive standpoint. At the same time, students of IT have been exposed to, and educated in, a discussion of the multitude of variables that can impact an organization's effectiveness. We have seen how IT can compete better with its rivals, suppliers, buyers, and potential entrants. We have seen how IT can impact organizational effectiveness by considering contributory studies from the fields of sociology, psychology, engineering, organizational behavior, and especially management. From this research, it became apparent, as Orlikowski and Baroudi (1991) indicated, that various research philosophies "... can offer an insightful perspective on the phenomena of interest in information systems research."

Researchers of IT have made great strides in identifying and isolating those variables which can advance the study of information technology and its contribution to the success of an organiza- 
tion. This practice needs to continue and all internal and external variables which could have an impact on the potential success of an organization need to be considered in order to promote the use of IT for the good of the organization and the individuals in the organization. This research can make a contribution to the study on the influence of culture and IT on an organization, and those variables that we need to understand.

As Fiedler et al. (1996), point out, "Further research is needed into the ultimate benefits of matching IT and organization structure." The research presented here will contribute to the advancement of IT and organizational success, in that "IT has both social and material properties, being physically and socially constructed by subjective human action, while also objectified and reified through institutionalization" ( Orlikowski \& Robey, 1991). In essence, the cultural orientation of the individual operating within his culture is a major key variable to consider in the implementation of Information Systems.

\section{Bibliography}

Benson-Armer, R. \& Hsieh, T.Y. (1997). Teamwork across time and space. The McKinsey Quarterly, Autumn, (4), p. 18-27.

Brown, T. E., Williams, R. K. \& Brown, J. T. (1998). A comparison of attitudes toward computers among business professionals in China, Japan, and the United States. Journal of Computer Information Systems, xxxviii(3), 1-5.

Cartwright, S. \& Cooper, C. L. (1989). Predicting success in joint venture organisations in information technology. Journal of General Management, 15(1), 39-52.

Davis, F. (1989). Perceived ease of use and user acceptance of information technology. MIS Quarterly, 13(3), 319-339.

Daft, R. L. \& Lengel, R. H. (1986). Organizational information requirements, media richness and structural design. Academy of Management Journal, 32(5), 554-571.

DeLone, W. H. \& McClean, E. R. (1992). Information systems success: The quest for the dependent variable. Information Systems Research, 3(1), 60-90.

Ejias, R. J., Shepherd, M. M., Vogel, D. R. \& Lazaneo, L. (1996-1997). Consensus and perceived satisfaction levels: A cross-cultural comparison of GSS and non-GSS outcomes within and between the United States and Mexico. Journal of Management Information Systems, 13(3), 163-207.

Ferraro, G. P. (1994). The cultural dimensions of international business (2nd ed.). NJ.

Fishbein, M. \& Ajzen, I. (1975). Belief, attitude, intention and behavior: An introduction to theory and research. Reading, MA: Addison-Wesley.

Fiedler, K. D., Grover, V. \& Teng, J. (1996). An empirically derived taxonomy of information technology structure and its relationship to organizational structure. Journal of Management Information Systems, 13(1), 9-34.

Francesco, A. M. \& Gold, B. A. (1998). International organizational behavior. NJ: Prentice Hall.

Gannon, M. J. and Associates. (1994). Understanding global cultures: Metaphorical journeys through 17 countries. CA: Sage Publication.

Grover, V., Segars, A. H. \& Durand, D. (1994). Organizational practice, information resource deployment and systems success: A cross-cultural survey. Journal of Strategic Information Systems, 3(2), 85-106.

Hall, E. T. (1976). Beyond culture. NY: Anchor Press.

Harrison, R. (1975). Understanding your organization's character. In Harvard Business Review on Management. New York: Harper \& Row. 
Hofstede, G. (1993). Cultural constraints in management theories. Academy of Management Executive, 7, 81-94.

Hunger, J. D. \& Wheelen, T. L. (1996). Strategic management. New York: Addison-Wesley.

Johnston, H. R. \& Carrico, S. R. (1988).Developing capabilities to use information strategically. MIS Quarterly, 12(1), 37-88.

Karuranga, E., Su, Z. \& Beauregard, R. (2006). Technological innovations and diffusion in China. Proceedings of the Academy of Management, pp. X1-X6.

Kettinger, W., Chong, J., Lee, C. \& Lee, S. (1995). Global measures of information service quality: A cross-national study. Decision Sciences, 26(5), 569-588.

Kitchell, S. (1995). Corporate culture, environmental adaptation, and innovation adoption: A qualitative/quantitative approach. Journal of the Academy of Marketing Science, 23(3), 195-205.

Kluckhohn, F. \& Strodtbeck, F. L. (1961). Variations in value orientations. Peterson, Ill..

Mahmood, M. A. \& Soon, S. K. (1991). A comprehensive model for measuring the potential impact of information technology on organizational strategic variables. Decision Sciences, 22(4), 869-897.

Markus, M. L. \& Robey, D. (1988). Information technology and organizational change: Causal structure in theory and research. Management Science, 34(5), 583-598.

Merchant, J. E. (1997). Determinants of corporate success: One view of comparative work values of Australians and Americans. Proceedings of the Fourth International Meeting, Decision Sciences Institute, Sydney, Australia, July, 1997.

Mintzberg, H., Quinn, J. B. \& Voyer, J. (1995). The strategy process. New Jersey: Prentice-Hall.

Orlikowski, W. J. \& Baroudi, J. (1991). Studying information technology in organizations: Research approaches and assumptions. Information Systems Research, 2(1), 1-28.

Orlikowski, W. J. \& Robey, D. (1991). Information technology and the structuring of organizations. Information Systems Research, 3(2), 143-169.

Robichaux, B. P., \& Cooper, R. B. (1998). GSS participation: A cultural examination. Information and Management, 33, 287-300.

Rockart, J. F. \& Scott-Morton, M. (1984). Implications of changes in information technology for corporate strategy. Interfaces, 14(1), 84-95.

Srite, M. \& Karahanna, E. (2006). The role of espoused national cultural values in technology acceptance. MIS Quarterly, 30(3), 679-704.

Straub, D. W. (1994). The effect of culture on IT diffusion: E-Mail and FAX in Japan and the U.S. Information Systems Research, 5(1), 23-47.

Straub, D. W., Keil, M., \& Brenner, W. H. (1997). Testing the technology acceptance model across cultures: A three country study. Information Management, 33, 1-11.

Swanson, E. B. (1987). Information systems in organization theory: A review. Critical Issues in Information Systems Research (pp. 181-204). John Wiley and Sons.

Trompenaars, F. (1993). Riding the waves of culture: Understanding diversity in global business. London: The Economist Books.

Venkatesh, V. \& Davis, F. D. (2000). A theoretical extension of the technology acceptance model: Four longitudinal field studies. Management Science, 46(2), 186-204.

Watson, R.T., Ho, T.H., \& Raman, K.S. (1994). Culture: A fourth dimension of group support systems. Communications of the ACM, 37, 44-55. 


\section{Biography}

Dr. Sylnovie Merchant received her Ph.D. in Information Systems and Quantitative Analysis from the University of Arkansas. She received her BS in Business and an MBA from California State University, Sacramento (CSUS). Dr. Merchant taught at California State University, Sacramento as an Associate Professor of Management Information Science and was actively involved in fundraising and community outreach for the college. She is currently an Associate Professor at Lynchburg College in Virginia and is involve in student development activities. Dr. Merchant's research interests include the diffusion of innovations, social network analysis, systems development, and the use of electronic commerce in small and medium sized businesses. She has authored three textbooks as well as several refereed journal articles and conference proceedings. Dr. Merchant served the editor of the International Journal of Business and Economics and serves as a reviewer for a number of journals. 